\title{
The efficiency of pig breeding by maturity and bacon thickness at different selection intensities
}

\author{
Andrey M. Ukhtverov*, Ismagil N. Khakimov, Ekaterina S. Zaitseva, Liubov F. Zaspa, and Elena S. Kanaeva \\ Samara State Agrarian University, Samara 446442, Russia
}

\begin{abstract}
Scientific and economic experience in the study of the comparative effectiveness of using simultaneous and sequential selection at its various intensities $(75,50$ and $30 \%$ in boars and $30 \%$ in breeding sows) by early maturity and thickness of bacon, aimed at improving feeding and meat qualities, established that simultaneous selection by a set of characters is possible, because connections between them in either the positive or the negative direction have not been identified. However, when one of the traits during prolonged selection improves by an excessive amount, other non-breeding traits deteriorate. At the same time, simultaneous and sequential selection by the early maturity and thickness of the bacon makes it possible to select the same animals for further breeding, regardless of the intensity of the rejection. A different level of producers' selection intensity $(75,50,30 \%)$ and the same breeding sows $(30 \%)$ in terms of early maturity and bacon thickness ensure an improvement in these characteristics by an unequal value during one generation.
\end{abstract}

\section{Introduction}

As it was often emphasized, a characteristic feature of modern pig breeding is the enhanced improvement of animals for feeding and meat qualities. [1,2]

The enhanced improvement of these two characteristics raises an issue under the way of the most rational selection simultaneously or sequentially for these two indicators. [3-8]

When complex of characters (early maturity and bacon thickness) breeding, animals can be selected simultaneously according to the studied parameters, as well as sequentially. When selecting according to the first option, an animal with a good manifestation of the first trait can be rejected from the herd, if the second trait has very low indicators.

In the second option, by selecting individuals in sequence, one can be freed from an undesirable livestock by one trait, but due to the presence of a negative correlative connection or its absence between these traits, many undesirable animals can remain in the herd by the second trait.

Data on a comparative experimental verification of these two selection methods effectiveness against the background of varying degrees of rejection male and female individuals are scarce. Therefore, the solution to this issue is relevant. [9, 10]

When breeding according to a set of characteristics (early maturity and thickness of bacon), animals can be selected simultaneously according to the studied parameters, as well as in tandem. When selecting according to the first option, an animal with a good manifestation of the first characteristic may be rejected from the herd, if the second characteristic has very low indicators. In the second option, selecting individuals sequentially (in tandem), one can be freed from an undesirable livestock according to one characteristic, but due to the presence of a negative connection or the absence of the connection between these characteristics, many animals, undesirable according to the second characteristic, may remain in the herd.

Based on this, the goal of our research was to study the comparative effectiveness of using simultaneous and sequential selection at different intensities $(75,50$ and $30 \%$ in boars and $30 \%$ in breeding sows) by early maturity and bacon thickness, aimed at improving feeding and meat qualities.

\section{Materials and methods}

Scientific and economic experiments were carried out in the breeding farm of Northern Key JSC of the Samara Region on replacement gilts of large white breed.

In the replacement of young animals (grunts and pigs) with a live weight of $100 \mathrm{~kg}$. the thickness of the salted fat was measured in vivo with the "specker" device at the level of 6-7 thoracic vertebra, and early maturity was calculated.

After carrying out this work, animals with exterior defects, patients with crater nipples and other defects were removed from the herd. This was done in order to prevent such animals from going into the livestock that was planned to be rejected according to the studied characteristics, that is, by the maturity and thickness of the fat. left.

For the experiment, 26 repair boars and 75 pigs were

\footnotetext{
* Corresponding author: andrei_uhtverov@mail.ru
} 
From the evaluated boars group, animals with the best manifestation of bacon thickness and early maturity at a selection pressure of 30,50 and $75 \%$ from boars and $30 \%$ from breeding sows were left for further use.

With the simultaneous selection of boars, the same animals remained in the first group, which had both early maturity and the bacon thickness; the animals of the first group were included in the second group and additionally included individuals with the best combinations of early maturity and bacon thickness to the previously calculated limit.

In the third group (30\% rejection) there were animals of the 1st and 2nd groups and got to the control livestock also the best by the studied characteristics. The breeding sows were selected on the same basis.

With a consistent selection of boars, animals are first rejected at $50 \%$ in maturity. Then $50 \%$ of the best bacon is also selected out of the remaining livestock. At the same time, $75 \%$ rejection of animals is achieved, taking into account both traits.

In the second group, at the beginning, $30 \%$ of boars were rejected by maturity, and then $30 \%$ of them by bacon thickness. This provides $50 \%$ rejection of individuals for fattening and meat qualities. For $30 \%$ rejection of the whole herd, it is necessary to select $17 \%$ of animals according to the studied characteristics. The principle of breeding sows' rejection is similar.

The specified limits of rejection in the second case ensure that the number of selected animals is the same as in the first case.

Principle diagram of evaluated animals rejection are shown in Table 1.

Table 1. Diagram of rejection and mating of experimental animals (\%)

\begin{tabular}{|c|c|c|c|c|c|c|c|}
\hline \multirow[b]{3}{*}{$\stackrel{2}{\stackrel{0}{3}}$} & \multirow[b]{3}{*}{ 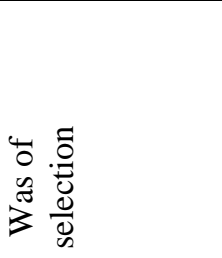 } & \multicolumn{3}{|c|}{ Boars } & \multicolumn{3}{|c|}{ Breeding sow } \\
\hline & & \multicolumn{3}{|c|}{ rejection by: } & \multicolumn{3}{|c|}{ rejection by: } \\
\hline & & $\begin{array}{c}\text { Early } \\
\text { maturity }\end{array}$ & $\begin{array}{c}\text { Bacon } \\
\text { thickness, } \\
\mathrm{cm}\end{array}$ & $\begin{array}{c}\text { Bacon } \\
\text { thickness }+ \\
\text { early maturity }\end{array}$ & $\begin{array}{c}\text { Early } \\
\text { maturity }\end{array}$ & $\begin{array}{c}\text { Bacon } \\
\text { thickness, } \\
\mathrm{cm}\end{array}$ & $\begin{array}{c}\text { Bacon } \\
\text { thickness }+ \\
\text { early maturity }\end{array}$ \\
\hline 1 & $\begin{array}{c}\text { Simultaneous } \\
\text { Sequential }\end{array}$ & 50 & 50 & $\begin{array}{l}75 \\
75\end{array}$ & 17 & 17 & $\begin{array}{l}30 \\
30\end{array}$ \\
\hline 2 & $\begin{array}{c}\text { Simultaneous } \\
\text { Sequential }\end{array}$ & 30 & 30 & $\begin{array}{l}50 \\
50 \\
\end{array}$ & 17 & 17 & $\begin{array}{l}30 \\
30 \\
\end{array}$ \\
\hline 3 & $\begin{array}{c}\text { Simultaneous } \\
\text { Sequential }\end{array}$ & 17 & 17 & $\begin{array}{l}30 \\
30 \\
\end{array}$ & 17 & 17 & $\begin{array}{l}30 \\
30 \\
\end{array}$ \\
\hline 4 & No selection & 0.0 & 0.0 & 0.0 & 0.0 & 0.0 & 0.0 \\
\hline
\end{tabular}

\section{Results}

The change in breeding traits of animals in experimental groups according to the selection results is shown in Table 2 . The presented materials discuss changes in the average values of early maturity and bacon thickness in connection with the intensity of selection, as well as the value of these indicators at the same intensity of selection, but carried out by different methods (sequential or simultaneous).

It turned out that as the selection pressure intensifies, the average values taken into account characters change in the direction where the selection is directed.

For example, if the early maturity and thickness of the fat at the selected boars at $75 \%$ of rejection averaged 187.3 days and $2.36 \mathrm{~cm}$, the bacon thickness, respectively, then these characteristics at $30 \%$ of rejection were much worse and amounted to 201.7 days and $2.81 \mathrm{~cm}$, and in the absence of selection they were at the level of 203.8 days and $2.89 \mathrm{~cm}$.

As for the uterus, the selection intensity in all cases was the same at the level of $30 \%$, therefore, the average values of bacon thickness and early maturity were approximately the same, however, in the fourth group, where selection was not carried out, early maturity was worse by 6-7 days $(\mathrm{P}<0.05)$ and the bacon thickness at 0.05-0.12 cm (P> 0.05).

As for the comparison of arithmetic values of individuals selected after using different methods, but with the same selection pressure, no difference was found between individuals of different subgroups.

It can be seen that both sequential and simultaneous selection allows selecting animals with almost the same value. Small, even minimal differences were insignificant among both the boars and the Breeding sow stock.

For more clear data about the effectiveness of different selection intensity levels, the values of breeding differentials were calculated by different methods of selecting pigs for the bacon thickness and early maturity (Table 3).

The data presented in Table 3 indicate that the difference between the selected animals and the average indicators for the whole group varies depending on the strength of the selection pressure.

If among boars at $75 \%$ of their rejects, the early maturity differential was at the level of $16.7-19.1 \%$, then 
with $30 \%$ selection of undesirable animals, these indicators significantly decrease and amount to: $0.1-1.2 \%$ of early maturity, $0.7-4.9 \%$ of bacon thickness, i.e. the differential indicator decreases 12 times in maturity and 7-8 times in the thickness of the fat.

As for the breeding sows, where the rejection rate in all groups was the same and amounted to $30 \%$, the differential value did not differ much depending on the animals belonging to one or another group and ranged from: $2-3 \%$ of early maturity, $3-5 \%$ of fat thickness.

The absolute breeding differential index was practically independent from the method of selecting the best animals both among boars and among breeding sows. The created superiority in early maturity and bacon thickness using sequential and simultaneous selection was almost the same. Fluctuations within $0.1-1.0 \%$ should be considered insignificant.

Table 2. The bacon thickness and early maturity of experimental pigs with a different selection and its intensity

\begin{tabular}{|c|c|c|c|c|c|c|c|}
\hline \multirow[t]{2}{*}{ Group } & \multirow{2}{*}{$\begin{array}{c}\text { Way of } \\
\text { selection }\end{array}$} & \multicolumn{3}{|c|}{ Boars } & \multicolumn{3}{|c|}{ Breeding sow } \\
\hline & & $\begin{array}{c}\% \text { of } \\
\text { rejection }\end{array}$ & $\begin{array}{c}\text { Early } \\
\text { maturity, } \\
\text { days }\end{array}$ & $\begin{array}{c}\text { Bacon } \\
\text { thickness, } \\
\mathrm{cm}\end{array}$ & $\begin{array}{c}\% \text { of } \\
\text { rejection }\end{array}$ & $\begin{array}{c}\text { Early maturity, } \\
\text { days }\end{array}$ & $\begin{array}{c}\text { Bacon } \\
\text { thickness, } \\
\mathrm{cm}\end{array}$ \\
\hline 1 & $\begin{array}{l}\text { Simultaneous } \\
\text { Sequential Average }\end{array}$ & $\begin{array}{l}75 \\
75 \\
75\end{array}$ & $\begin{array}{l}187.4 \pm 0.75 \\
187.1 \pm 1.47 \\
187.3 \pm 0.83\end{array}$ & $\begin{array}{l}2.33 \pm 0.04 \\
2.40 \pm 0.03 \\
2.36 \pm 0.03\end{array}$ & $\begin{array}{l}30 \\
30 \\
30\end{array}$ & $\begin{array}{l}231.1 \pm 3.23 \\
231.1 \pm 4.23 \\
231.1 \pm 2.62\end{array}$ & $\begin{array}{l}2.94 \pm 0.15 \\
2.95 \pm 0.11 \\
2.94 \pm 0.09\end{array}$ \\
\hline 2 & $\begin{array}{l}\text { Simultaneous } \\
\text { Sequential Average }\end{array}$ & $\begin{array}{l}50 \\
50 \\
50 \\
\end{array}$ & $\begin{array}{l}198.5 \pm 3.60 \\
198.1 \pm 1.22 \\
198.3 \pm 1.84 \\
\end{array}$ & $\begin{array}{l}2.81 \pm 0.02 \\
2.75 \pm 0.02 \\
2.78 \pm 0.02\end{array}$ & $\begin{array}{l}30 \\
30 \\
30\end{array}$ & $\begin{array}{l}233.4 \pm 4.39 \\
231.0 \pm 3.37 \\
232.2 \pm 2.69\end{array}$ & $\begin{array}{l}2.94 \pm 0.12 \\
2.90 \pm 0.08 \\
2.92 \pm 0.07\end{array}$ \\
\hline 3 & $\begin{array}{l}\text { Simultaneous } \\
\text { Sequential Average }\end{array}$ & $\begin{array}{l}30 \\
30 \\
30 \\
\end{array}$ & $\begin{array}{l}202.8 \pm 0.01 \\
200.6 \pm 1.07 \\
201.7 \pm 0.77\end{array}$ & $\begin{array}{l}2,74 \pm 0.04 \\
2.86 \pm 0.05 \\
2.81 \pm 0.04\end{array}$ & $\begin{array}{l}30 \\
30 \\
30\end{array}$ & $\begin{array}{l}232.6 \pm 4.11 \\
232.4 \pm 3.96 \\
232.5 \pm 2.75\end{array}$ & $\begin{array}{l}2.97 \pm 0.04 \\
2.94 \pm 0.10 \\
2.95 \pm 0.06\end{array}$ \\
\hline 4 & No selection & 0.0 & $203.8 \pm 1.91$ & $2.89 \pm 0.5$ & 0.0 & $238.8 \pm 1.96$ & $3.02 \pm 0.05$ \\
\hline Averas & $\begin{array}{l}\text { of all animals before } \\
\text { selection }\end{array}$ & 0.0 & $203.0 \pm 1.12$ & $2.88 \pm 0.03$ & 0.0 & $238.5 \pm 1.76$ & $3.06 \pm 0.05$ \\
\hline
\end{tabular}

Table 3. The value of the selection differential at different intensities and selection methods

\begin{tabular}{|c|c|c|c|c|c|c|c|c|c|c|c|}
\hline \multirow{3}{*}{ 气̊̆ } & \multirow{3}{*}{$\begin{array}{c}\text { Way } \\
\text { of selection }\end{array}$} & \multicolumn{5}{|c|}{ Boars } & \multicolumn{5}{|c|}{ Breeding sow } \\
\hline & & \multirow{2}{*}{$\begin{array}{c}\% \\
\text { of } \\
\text { rejectio } \\
n\end{array}$} & \multicolumn{2}{|c|}{ Early maturity } & \multicolumn{2}{|c|}{ Bacon thickness } & \multirow{2}{*}{$\begin{array}{c}\% \\
\text { of } \\
\text { rejection }\end{array}$} & \multicolumn{2}{|c|}{ Early maturity } & \multicolumn{2}{|c|}{$\begin{array}{l}\text { Bacon } \\
\text { thickness }\end{array}$} \\
\hline & & & days & $\%$ & $\mathrm{~cm}$ & $\%$ & & days & $\%$ & $\mathrm{~cm}$ & $\%$ \\
\hline \multirow[t]{3}{*}{1} & Simultaneous & 75 & 15.6 & 7.7 & 0.55 & 19.1 & 30 & 7.4 & 3.1 & 0.12 & 3.9 \\
\hline & Sequential & 75 & 15.9 & 7.8 & 0.48 & 16.7 & 30 & 7.4 & 3.1 & 0.11 & 3.6 \\
\hline & Average & 75 & 15.7 & 7.7 & 0.52 & 18.0 & 30 & 7.4 & 3.1 & 0.12 & 3.7 \\
\hline \multirow[t]{3}{*}{2} & Simultaneous & 50 & 4.5 & 2.2 & 0.07 & 2.43 & 30 & 5.1 & 2.1 & 0.12 & 3.9 \\
\hline & Sequential & 50 & 4.9 & 2.4 & 0.13 & 4.51 & 30 & 7.5 & 3.1 & 0.16 & 5.3 \\
\hline & Average & 50 & 4.7 & 2.3 & 0.10 & 3.47 & 30 & 6.3 & 2.6 & 0.14 & 4.6 \\
\hline \multirow[t]{3}{*}{3} & Simultaneous & 30 & 0.2 & 0.1 & 0.14 & 4.86 & 30 & 5.9 & 2.5 & 0.09 & 3.0 \\
\hline & Sequential & 30 & 2.4 & 1.2 & 0.02 & 0.69 & 30 & 6.1 & 2.6 & 0.12 & 3.9 \\
\hline & Average & 30 & 1.3 & 0.6 & 0.07 & 2.43 & 30 & 6.0 & 2.5 & 0.11 & 3.6 \\
\hline
\end{tabular}

The considered differentials' values suggest the possibility of their successful use in practical selection. Of course, $75 \%$ rejection provides a reliable superiority of the selected individuals over the average herd and can be used in practical breeding.

However, in the future, with a decrease in rejection power among boars, the differential value decreases sharply. So, at $50 \%$ selection, the superiority in the bacon thickness was $4.5-2.4 \%$, or 5.2 times less than the highest rejects, and 3.3 times in maturity. $30 \%$ rejection does not provide practically significant superiority over the average herd performance: $1.3 \%$ in early maturity and $2.4 \%$ in bacon thickness.
With the magnitude of the selection differential, which is obtained at $30 \%$ rejection, it is not possible to expect the desired shift of the breeding traits towards their improvement. 50\% rejection of boars is also not reliable in breeding to improve their feeding and meat qualities.

As for the breeding sows, at $30 \%$ of their rejects, the values of the selection differentials both in maturity and in the bacon thickness are much higher than in boars, not only at $30 \%$ rejection, but also when half of the undesirable boars are removed from the herd.

In the first case, they are 3-5 times higher in maturity, and in the second case they are either the same or 1.2-1.3 times higher. It could be explained by the unequal 
requirement presented to replacement gilts and pigs by specialists. The fact is that among the boars there has always been a more severe rejection of unwanted individuals than among breeding sows.

The breeder in his work leaving the best animals always tries to have the most aligned animals. At the same time, the presence of record individuals in the herd is not excluded.

This made some of the animals with the best early maturity and bacon thickness to be selected at the level of $75 \%$; therefore, the differential value was the highest. The rest of the livestock mainly had indicators at the level of herd averages or slightly higher than them.

Among breeding sows, traditionally intensive selection is not carried out, since otherwise the situation with further reproduction of the herd would have become more complicated. In addition, it is well known that the improvement of the herd or the whole population (breed) has always been mainly through producers, therefore, attention to them has always been increased.

The reproductive abilities of the boars and breeding sows selected at different breeding pressures for early maturity and bacon thickness are shown in tables 4 and 5 without dividing the animals into subgroups according to the selection method.
The presented indicators show somewhat ambiguous results based on the results of bucking the breeding sows by boars that have passed an unequal selection barrier in terms of early maturity and bacon thickness.

According to the results of the first buck (15-16 breeding sows in each group), there is a tendency for a worse manifestation of the fertilizing ability in boars that are characterized by the better indicators of early maturity and bacon thickness. In the first group, where boars were used with very good indicators of the development of bacon thickness and early maturity, the conception rate for the first time was $66.6 \%$.

Subsequently, as the pressure on fattening and meat qualities decreases, the fertilizing ability of the boars increases in the second and third groups, where the boars were rejected at the levels of 50 and $30 \%$, the conception rate was $75.0-73.3 \%$ and practically did not differ from that of the animals from the fourth (control) group. According to the results of the second bucking, no noticeable differences between the groups are observed; however, according to the results of both buckings, in the first group, the indicators of successful mating are noticeably worse.

Table 4. Fertilizing ability of boars with different levels of development of bacon thickness and early maturity

\begin{tabular}{|c|c|c|c|c|c|c|}
\hline Group & rejection \% & Early maturity, & \multirow{2}{*}{$\begin{array}{c}\text { Bacon } \\
\text { days }\end{array}$} & thickness, cm & \multicolumn{3}{|c|}{ Fertilized breeding sows, \% } \\
\cline { 5 - 7 } & & & & $\begin{array}{c}\text { First } \\
\text { bucking }\end{array}$ & $\begin{array}{c}\text { Second } \\
\text { bucking }\end{array}$ & total \\
\hline 1 & 75 & 187 & 2.36 & 66.6 & 13.4 & 80.0 \\
\hline 2 & 50 & 198 & 2.78 & 75.0 & 12.5 & 87.5 \\
\hline 3 & 30 & 202 & 2.81 & 73.3 & 20.0 & 93.3 \\
\hline 4 & 0.0 & 204 & 2.89 & 75.0 & 12.5 & 87.5 \\
\hline
\end{tabular}

After the experiment was completed, there was no further control by the authors over the use of experimental boars. However, some of them were transferred by the zootechnical service to the main herd. We used the production data which were fixed according to generally accepted zootechnical records.

The number of boars used was much smaller; we could not reliably establish the reasons for their disposal or noninclusion in the main herd. Nevertheless, the data presented in table 5 can serve as an indirect confirmation of their effective use in the production environment for 1.5 years.

The data presented indicate that, according to the fertilizing ability, the boars from the first group were characterized by slightly worse indicators. They were lower than in other groups by $5-7 \%$.

The boars from the remaining groups did not practically differ from each other by the percentage of successful mating with the breeding sows, and this indicator ranged from 83 to $85 \%$.

There is a noticeable tendency to obtain a somewhat smaller number of piglets per farrow from the breeding sows bucked by the boars that have high rates of development of the thickness of bacon and early maturity.

When considering the development of piglets up to two months old, we did not find any regular differences between the groups depending on the early maturity and bacon thickness of the breeders.

Table 5. Fertilizing abilities of boars with a different level of development of early maturity and bacon thickness

\begin{tabular}{|c|c|c|c|c|c|c|}
\hline \multirow[t]{2}{*}{ Group } & \multicolumn{2}{|c|}{ Number of animals } & \multirow{2}{*}{$\begin{array}{c}\text { Conception } \\
\text { rate of } \\
\text { breeding sows, } \\
\%\end{array}$} & \multirow{2}{*}{$\begin{array}{l}\text { prolificacy, } \\
\text { animals }\end{array}$} & \multicolumn{2}{|c|}{2 months old } \\
\hline & boars & $\begin{array}{c}\text { Breeding } \\
\text { sows }\end{array}$ & & & $\begin{array}{c}\text { Number of piglets, } \\
\text { animals }\end{array}$ & $\begin{array}{c}\text { Mass of one } \\
\text { animal, kg }\end{array}$ \\
\hline 1 & 6 & 18 & 78 & 10.5 & 8.5 & 19.6 \\
\hline 2 & 7 & 33 & 85 & 10.8 & 9.1 & 19.4 \\
\hline 3 & 6 & 24 & 83 & 10.7 & 8.9 & 20.1 \\
\hline 4 & 2 & 27 & 85 & 10.8 & 8.9 & 19.8 \\
\hline
\end{tabular}


The mass of one two-month-old piglet ranged from 19.4 to $20.1 \mathrm{~kg}$, and their safety - from 81 to $84 \%$. Thus, the production data also indirectly confirm a slightly worse manifestation of the fertilizing ability of the boars with a very high development of early maturity and bacon thickness.

Next, we studied the reproductive abilities of the breeding sows that were selected with their $30 \%$ rejection according to the bacon thickness and early maturity and bucked by the breeder boars after their rejection by the same characteristics by 75.50 and $30 \%$.

Although the experimental animals did not directly experience selection pressure for reproductive abilities, the results obtained are ambiguous in the experimental groups.

Prolificacy was improving as the selection of boars for feeding and meat qualities became weaker. While in the first group it amounted to 10.6 animals per farrow, then in the third group, where the breeding sows were bucked by the boars that had gone through 30\% of rejection, prolificacy was at the level of 10.9 animals and did not differ from that of the animals from the fourth group where there was no selection. Although the obtained difference of 0.3 animals was unreliable, however, this fact indicates a tendency for a better manifestation of this characteristic in those groups where a more sparing level of rejection for meat and fattening qualities was applied to the parents.

\section{Conclusion}

Thus, simultaneous selection by a set of characters is possible, because no connections between them in either the positive or negative direction have been identified. However, when one of the traits during prolonged selection improves by an excessive amount, other nonbreeding traits deteriorate.

At the same time, simultaneous and sequential selection by the early maturity and thickness of the bacon makes it possible to select the same value animals for further breeding, regardless of the intensity of the rejection.

A different level of producers' selection intensity ( 75 , $50,30 \%)$ and the same uterus (30\%) in terms of early maturity and thickness of the fat ensure an improvement in these characteristics by an unequal value in one generation.

\section{References}

1. A.M. Ukhtverov, E.S. Zaitseva, L.F. Zaspa, Influence of pigs' different selection on the meat quality of their offspring Bulletin of the Samara State Agricultural Academy 1, 144-146 (2015)

2. A.M. Ukhtverov, Kh.B. Baimishev, I.N. Khakimov, V.S. Grigorev, A.T. Varakin, Duration of economic use of uterine with the different levels of fat depth and early maturity Research J. of Pharmaceutical, Biological and Chemical Sciences 9(5), 935-942 (2018)

3. H. Koknaroglu, T. Akunal, Animal welfare: An animal science approach Meat Science 95(4), 821-827 (2013)

4. K. Szulc et al., Evaluation of fattening and slaughter performance and determination of meat quality in Ztotnicka Spotted pigs and their crosses with the Duroc breed Czech J. of Animal Science 57(3), 95107 (2012)

5. C. Pugliese, F. Sirtori, Quality of meat and meat products produced from southern European pig breeds Meat science 90(3), 511-518 (2012)

6. G. Maiorano et al., Influence of rearing system, diet and gender on performance, carcass traits and meat quality of Polish Landrace pigs Animal 7(2), 341-347 (2013)

7. T. Kwon et al., Tracing the breeding farm of domesticated pig using feature selection (Sus scrofa) Asian-Australasian j. of animal sciences 30(11), 1540 (2017)

8. M. Đikić et al., Biological characteristics of turopolje pig breed as factors in renewing and preservation of population Stočarstvo 64(2-4), 79-90 (2010)

9. J. Faure et al., Consequences of divergent selection for residual feed intake in pigs on muscle energy metabolism and meat quality Meat science 93(1), 3745 (2013)

10. Y.M. Choi et al., Growth, carcass, fiber type, and meat quality characteristics in Large White pigs with different live weights Livestock Science 155(1), 123129 (2013) 